\title{
MICROWAVE SYNTHESIS OF SILVER NANOPARTICLES BY POLYOL METHOD AND TESTING THEIR SYNERGISTIC ANTIBACTERIAL ACTIVITY IN THE PRESENCE OF VANCOMYCIN
}

\author{
MALATHY D*, MEYAPPAN REVATHI, LETTICIA M \\ Department of Chemistry, School of Basic Sciences, VISTAS, Pallavaram, Chennai - 600 117, Tamil Nadu, India. \\ Email: dm.malathy@gmail.com
}

Received: 07 May 2018, Revised and Accepted: 20 June 2018

\section{ABSTRACT}

Objective: The aim of this study is to prepare silver nanoparticles (AgNPs) and nanorods using polyol under microwave heating method.

Methods: The synthesized nanoparticles were characterized using UV-visible, infrared spectral studies (Fourier-transform infrared [FTIR]), scanning electron microscopy (SEM), and transmission electron microscopy (TEM). Finally, the antibacterial activity of polyethylene glycol (PEG) protected AgNPs, against a series of Gram-positive and Gram-negative bacteria, was studied.

Results: From UV-visible spectroscopy studies, the growth rate of AgNPs was confirmed by measuring the change in absorbance of plasmon peak shape at different time intervals. FTIR spectroscopy studies showed the changes in the metal and the capping agents. SEM and TEM images revealed that very stable colloidal solutions of AgNPs with almost spherical and rod shape along with high monodispersity can be obtained with PEG protected AgNPs. Finally, the antibacterial activity of PEG protected AgNPs was investigated, which showed a synergistic role for the AgNPs along with vancomycin.

Conclusion: Uniform and stable polymer protected AgNPs were synthesized using ethylene glycol, triethylene glycol, and PEG as reducing agent in the presence of polyvinylpyrrolidone.

Keywords: Polyol, Silver nanoparticles, Ethylene glycol, Triethylene glycol, Polyethylene glycol.

(C) 2018 The Authors. Published by Innovare Academic Sciences Pvt Ltd. This is an open access article under the CC BY license (http://creativecommons. org/licenses/by/4. 0/) DOI: http://dx.doi.org/10.22159/ajpcr.2018.v11i10.27174

\section{INTRODUCTION}

Nanotechnology is one of the fascinating areas of research in the last few decades. During the past two decades, considerable attention has been paid to the synthesis of metal nanoparticles due to their unique optical, magnetic, electronic, catalytic properties, and applications [1]. A number of methods have been developed for the preparation of nanoparticles including citrate method [2], radiolytic reduction [3], sonochemical method [4], microemulsion route [5], polyol process [6], alcohol reduction [7], microwave (MW) [8], and green synthesis [9]. Among these, MW synthesis approach is considered to be a green chemistry approach for the synthesis of metal nanoparticles because of its fast and large-scale synthetic capabilities. Polyol process involves the reduction of the soluble silver species by ethylene glycol and other polyhydric alcohols, nucleation of metallic silver, and growth of the individual nuclei in the presence of a suitable protective agent [10]. A variety of polymers can be used as protective agents such as polyvinyl alcohol, polyacrylic acid, polyvinyl pyrrolidone (PVP), and polyethylene glycol (PEG), which are used to stabilize the silver nanoparticles (AgNPs) [11]. The presence of this capping agent is also essential for preventing the coalescence of the nuclei during the growth steps. Some of the important considerations in this method include avoiding the particle-particle adhesion and sintering during the nucleation and growth of the AgNPs and prevention of sintering of the particles by adding a required amount of protective agent. It has been reported that PEG is an excellent protective agent for the synthesis of metal nanoparticles in aqueous medium without adding any external reducing agent [12]. The polymers are biocompatible, odorless, nonvolatile, and non-irritating. It has been known that ethylene glycol and PEG are environmentally benign materials. They have been widely used in pharmaceutical industry as solvents, dispersing agents, ointments, etc. Ethylene glycol and its derivatives including PEG play a dual role as stabilizing agent as well as reducing agent because it is made of building blocks of ethylene glycol units. In this paper, we have developed a novel synthesis route to reduce silver nitrate $\left(\mathrm{AgNO}_{3}\right)$ using polyol method under MW irradiation.

\section{METHODS}

Chemicals

$\mathrm{AgNO}_{3}$ was used as a precursor of Ag particles. PVP was used as the stabilizing agent. PEG was used as reducing as well as protective agent. Potassium chloride and ferric chloride were used as solvents. All the chemicals were used as received from the suppliers without further purification.

\section{Instrumentation}

The UV-visible absorption spectrum was recorded on a Perkin-Elmer UV visible spectrophotometer Lambda 35 in the range of 190-1100 nm at a scan rate of $480 \mathrm{~nm} / \mathrm{min}$. Infrared spectra of the complexes are taken in potassium bromide disc using Shimadzu Fourier transform infra-red (FTIR) Spectrometer. Scanning electron microscopy (SEM) was carried out using JOEL-JSM-6360 instrument. The transmission electron microscopy (TEM) was recorded on ZOEL (100) instrument. The antibacterial studies were carried out using Kirby-Bauer test.

\section{Experimental procedures}

MW synthesis of AgNPs using ethylene glycol, triethylene glycol, and PEG 600

Various concentrations of PVP (20 mg, $30 \mathrm{mg}$, and $50 \mathrm{mg}$ ) were used with the same concentration of $\mathrm{AgNO}_{3}(10 \mathrm{mg})$. A known amount of PVP was dissolved in $20 \mathrm{ml}$ of ethylene glycol, triethylene glycol, and PEG 600. To synthesize polymer protected Ag cluster under MW mode, a domestic oven of frequency $2450 \mathrm{MHz}$ was operated in a cyclic mode to prevent intense boiling of solvents as well as aggregation of metals. 
Then, $10 \mathrm{mg}$ of $\mathrm{AgNO}_{3}$ was added to the hot PVP solution and irradiated by the MW oven. The temperature increased linearly and rapidly at a fast heating rate and reached $200^{\circ} \mathrm{C}$ after 1 min with the formation of yellow-colored silver colloids. Thus, the reaction was carried out only for $1 \mathrm{~min}$. At the end of the reaction, the medium was rapidly cooled in running water until room temperature was reached. The prepared colloidal solution of Ag clusters was used for further characterization. Similarly, the above set of procedure was repeated for 5 times and characterized.

MW synthesis of AgNPs in PEG 600 in the presence of $0.1 \mathrm{M} \mathrm{KCl}$ and $0.1 \mathrm{M} \mathrm{FeSO}_{4}$

4-5 drops of $\mathrm{Kcl}$ and $\mathrm{FeSO}_{4}$ was added to $50 \mathrm{mg}$ of PVP was dissolved in $20 \mathrm{ml}$ of PEG and heated in the MW oven. Then, $10 \mathrm{mg}, 20 \mathrm{mg}$, or $30 \mathrm{mg}$ of $\mathrm{AgNO}_{3}$ was added to the hot PVP solution and irradiated by MW oven. The temperature increased linearly and rapidly at a fast heating rate and reached $200^{\circ} \mathrm{C}$ after $1 \mathrm{~min}$ with the formation of yellow-colored silver colloids. Thus, the reaction was carried out only for 1 min. Similarly, the above set of the procedure was repeated for 5 times. The final colloidal solution was cooled to room temperature and used for further characterizations. Same concentrations of PVP $(50 \mathrm{mg})$ were used with various concentrations of $\mathrm{AgNO}_{3}(10,20$, and $30 \mathrm{mg})$.

\section{Vancomycin AgNPs}

4-5 drops of $\mathrm{KCl}$ and $20 \mathrm{mg}$ of PVP were dissolved in $20 \mathrm{ml}$ of PEG, and $10 \mathrm{mg}$ of vancomycin was added. The mixture was heated in a MW oven. Then, $10 \mathrm{mg}$ of $\mathrm{AgNO}_{3}$ was added to the hot PVP solution and irradiated by MW for $1 \mathrm{~min}$. The final colloidal solution was cooled to room temperature and further characterized.

\section{RESULTS AND DISCUSSION}

UV-visible spectral studies

It is one of the most widely used techniques for structural characterization of AgNPs. The formation of AgNPs was verified by UVVisible spectroscopy where an intense band centered at about $415 \mathrm{~nm}$ was clearly detected and their intensity increased with increasing metal salt-to-polymer ratio and also with increasing units of polymer. This band was identified as a surface plasmon resonance is due to a collective excitation of the free electrons in the nanoparticles. The shape of the plasmon band is almost symmetrical, suggesting that the nanoparticles are well dispersed and spherical. When the frequency of the electromagnetic field becomes resonant with the coherent electron motion, a strong absorption takes place, which is the origin of the observed color. Here, the color of the prepared AgNPs is yellow [13]. The change in UV-Visible absorption indicates that the size and dispersion of AgNPs were affected by both the concentration of polymer and $\mathrm{AgNO}_{3}$. Polymers are used as a protective medium for the colloids, and it affects the molecular motion of reduced silver and expected to be adsorbed on the surface of silver particles and subsequently limits the aggregation of colloids [14]. The formation of AgNPs could be achieved in a solution of PEG, and the time required for this reaction was only about $2 \mathrm{~min}$. To achieve colloidal silver dispersions with a narrow size distribution and free of sintering, small amounts of PVP were required. When the number of glycol units increases, the viscosity increases and also reducing property increases. Figs. 1-5 compares the absorption spectra obtained for three different PVP concentrations with the same concentration of $\mathrm{AgNO}_{3}$. The binding of vancomycin antibiotic on PEG-protected AgNP surface which was confirmed by UV-Visible spectral studies is shown in Fig. 6. It is found that only one symmetric absorption peak around $420 \mathrm{~nm}$ was observed, which is mainly attributable to primary dipolar excitation. Therefore, PEG-protected AgNPs under MW irradiation were further confirmed by SEM and TEM studies.

\section{(FTIR spectroscopy)}

FTIR spectroscopy was used to analyze the interactions between the metal and polymer. The wavelength of light absorbed is characteristic of the chemical bond present in the chemicals. By interpreting the infrared absorption spectrum, the chemical bonds in a molecule can

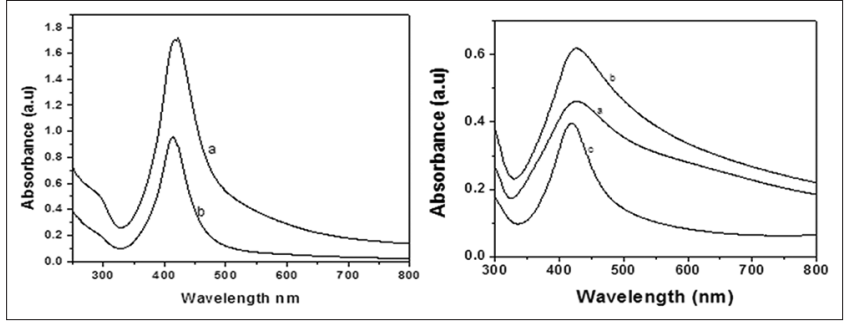

Fig. 1: (A and B) UV-visible absorption spectra of silver nanoparticles growth in $1 \mathrm{~min}$ and $5 \mathrm{~min}$ microwave irradiation: Ethylene glycol $(20 \mathrm{ml})$ and silver nitrate $(10 \mathrm{mg})$ with different concentrations of polyvinyl pyrrolidone (a) 20, (b) 30 , (c) $50 \mathrm{mg}$

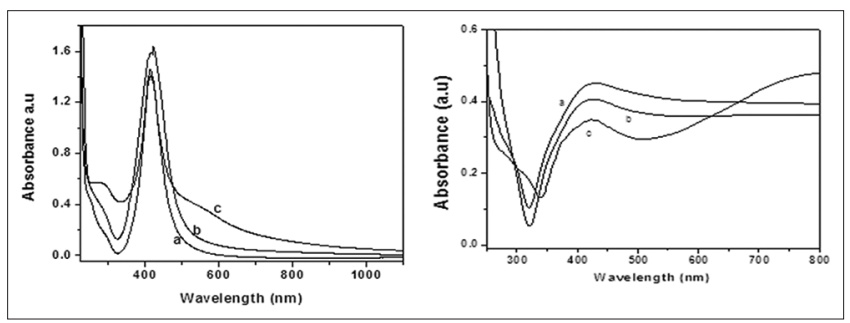

Fig. 2: (A and B) UV-visible absorption spectra of silver nanoparticles growth in $1 \mathrm{~min}$ and $5 \mathrm{~min}$ microwave irradiation:

Triethylene glycol $(20 \mathrm{ml})$ and silver nitrate $(10 \mathrm{mg})$ with different concentrations of polyvinyl pyrrolidone (a) 20, (b) 30, (c) $50 \mathrm{mg}$
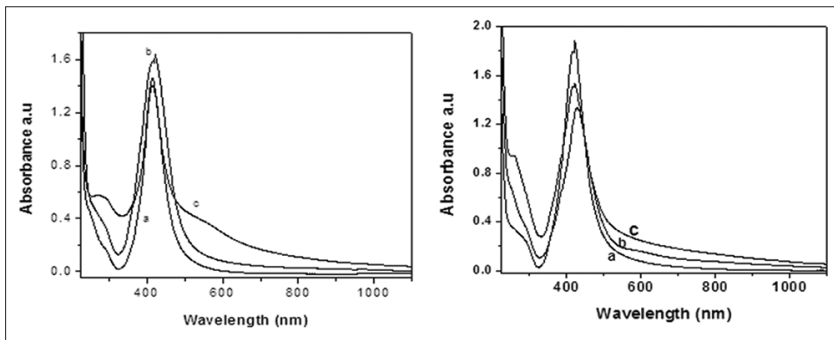

Fig. 3: (A and B) UV-visible absorption spectra of silver nanoparticles growth in $1 \mathrm{~min}$ and $5 \mathrm{~min}$ microwave irradiation: Polyethylene glycol $(20 \mathrm{ml})$ and silver nitrate $(10 \mathrm{mg})$ with different concentrations of polyvinylpyrrolidone (a) 20, (b) 30,

(c) $50 \mathrm{mg}(0.1 \mathrm{M} \mathrm{Kcl})$
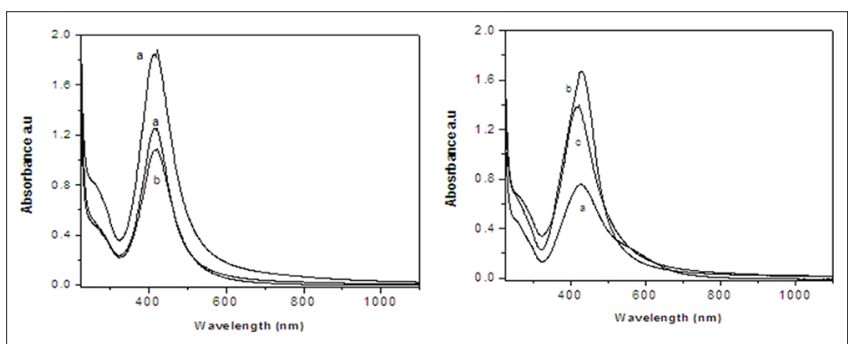

Fig. 4: (A and B) UV-visible absorption spectra of silver nanoparticles growth in $1 \mathrm{~min}$ and $5 \mathrm{~min}$ microwave irradiation:

Polyethylene glycol $(20 \mathrm{ml})$ and silver nitrate $(10 \mathrm{mg})$ with different concentrations of polyvinylpyrrolidone (a) 20, (b) 30 , (c) $50 \mathrm{mg}$ (0.1M FeSO4)

be determined. To further realize the role of PEG in the formation of AgNPs, in addition to that of a protective agent, the FTIR spectra for pure PEG and PEG-coated AgNPs were studied. For PEG spectrum in Fig. 7, the bands at 2872/cmcorrespond to $\mathrm{C}-\mathrm{H}$ stretching region in alkyl ether. A peaks at 1351 and $1485 / \mathrm{cm}$ indicate $\mathrm{CH}_{2}$ symmetric bending 
vibrations, and peak at $949 / \mathrm{cm}$ indicates C-O stretching vibrations. The peak at $1107 / \mathrm{cm}$ corresponds to $\mathrm{C}-\mathrm{O}-\mathrm{C}$ stretching vibrations. The bands at $3430 / \mathrm{cm}$ are attributed to the stretching vibration absorption of $-\mathrm{OH}$ of adsorbed water.

The IR spectrum of PEG-protected AgNPs is shown in Figs. 8 and 9. The reduction of silver ions in the solution can occur through the oxidation of hydroxyl groups of PEG to aldehyde groups $\left(\mathrm{CH}_{2} \mathrm{CH}_{2} \mathrm{OH} \rightarrow \mathrm{CH}_{2} \mathrm{CHO}\right)$. PEG has a clear stabilizing effect on the nanoparticles compared to shorter chain polymers. Silver colloids prepared using the monomer (ethylene glycol) need the addition of PVP to stabilize silver spherical nanoparticles. The presence of oxygen in the long chains can assist in the stabilization of the AgNPs. In Ag-PEG, increase in the intensity of the $\mathrm{C}=0$ peak was observed and the peak is observed at $1654 / \mathrm{cm}$ which is related to stretching vibration of $\mathrm{C}=0$, and this implies the

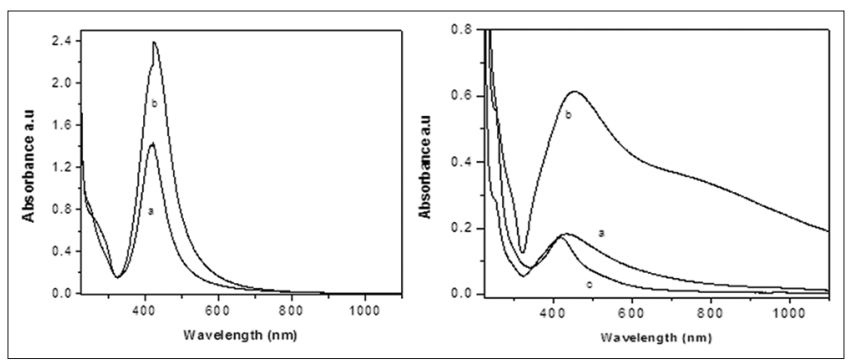

Fig. 5: (A and B) UV-visible absorption spectra of silver nanoparticles growth in $1 \mathrm{~min}$ and $5 \mathrm{~min}$ microwave irradiation:

Polyethylene glycol $(20 \mathrm{ml})$ and silver nitrate $(10 \mathrm{mg})$ with different concentrations of polyvinylpyrrolidone (a) 20, (b) 30 , (c) $50 \mathrm{mg}$

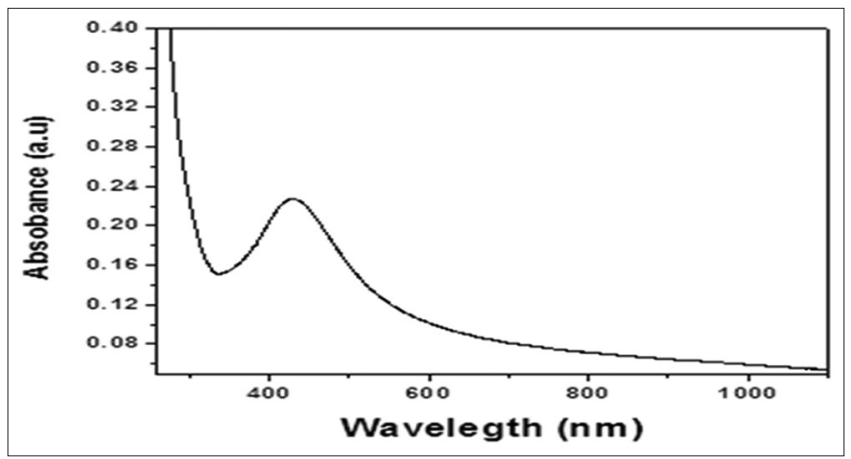

Fig. 6: UV-visible absorption spectra of silver nanoparticles growth in 1 min microwave irradiation: Polyethylene glycol (20 $\mathrm{ml})$ and silver nitrate $(10 \mathrm{mg})$ with $10 \mathrm{mg}$ vancomycin weak coordination chemical bonding between $\mathrm{C}=0$ and $\mathrm{Ag}$. This results indicate that PVP containing $\mathrm{N}-\mathrm{C}=\mathrm{O}$ molecules absorb on the surface of AgNPs through the formation of a coordination bond between silver and oxygen atom of the carbonyl groups in PVP. The peaks at 1956/ $\mathrm{cm}$ related to the substituted alkyl group and allene group, respectively, which also might be the products of PEG oxidation. The bands at $1109 / \mathrm{cm}$ corresponding to asymmetric and symmetric stretching vibration of C-N shift in PVP interacts with silver. The peaks at 1457/ $\mathrm{cm}$ indicate the carboxylate group of AgNPs. MW provides fast heating and thus accelerates the reduction of the metal cluster due to the rapid and homogeneous heating; a better and higher crystalline could be achieved. We suppose that both growth and nucleation phase occur simultaneously under MW irradiation condition because reaction time period is less. PVP, a protective polymer containing a $\mathrm{N}-\mathrm{C}=\mathrm{O}$ group, gets attached to the surface of silver. Different facets of silver will have different absorption ability. The facets containing fewer attached PVP molecules grow more rapidly than those with more PVP molecules. Hence, they tend to assemble one by one to fabricate a specific shape.

\section{SEM}

The surface morphology of the AgNPs was examined using SEM. Fig. 10 represents a SEM picture of PEG-protected AgNPs with $0.1 \mathrm{M} \mathrm{KCl}$ synthesized using MW method. It can be seen that AgNPs have welldefined monodispersed spherical and triangular shapes. The size of the AgNPs studied through SEM had sizes ranging from about 40-200 nm.

\section{TEM}

The size and morphology of the nanoparticles were analyzed with a transmission electron microscope. The typical TEM micrograph and the size distribution of the AgNPs were obtained from $20 \mathrm{ml}$ of PEG with $10 \mathrm{mg} \mathrm{AgNO}_{3}$ and $20 \mathrm{mg}$ of PVP and also with $0.1 \mathrm{M} \mathrm{Kcl}$ (Fig. 11). The resultant particles essentially were very fine with the mean diameter of $100 \mathrm{~nm}$. This revealed that PEG molecules indeed played the role of a protective agent for the formation of AgNPs. Further, it was observed that the morphology of the particles varied from rod, spherical, to triangular AgNPs when the reaction was changed from with to without addition of $\mathrm{KCl}$. Therefore, the addition of $\mathrm{KCl}$ has a profound influence on the morphology of the AgNPs.

\section{Antibacterial activity of PEG-protected AgNPs}

The antimicrobial action of AgNPs was evaluated using the disc diffusion or Kirby-Bauer method. Two Gram-positive strains of bacteria (Staphylococcus aureus and Micrococcus luteus) and two Gram-negative strains of bacteria (Escherichia coli and Klebsiella pneumonia) were used to study the antibacterial effect of the prepared nanoparticles as shown in Table 1. The antimicrobial activity of vancomycin increased in the presence of AgNPs against the strains. In the different Gram-positive and Gram-negative strains tested, vancomycin showed a synergistic enhancement in its antibacterial activity in the presence of AgNPs. The results further showed that the synergistic effect was more pronounced in K. pneumonia, S. aureus, and M. luteus. The enhanced activity of

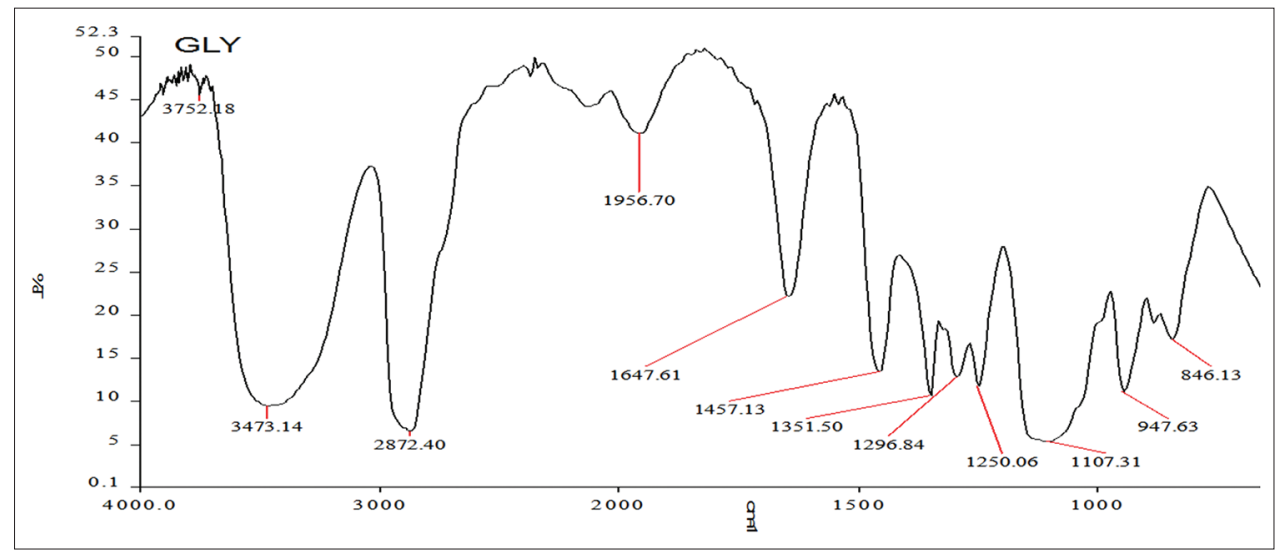

Fig. 7: Fourier-transform infrared spectrum of pure ethylene glycol 


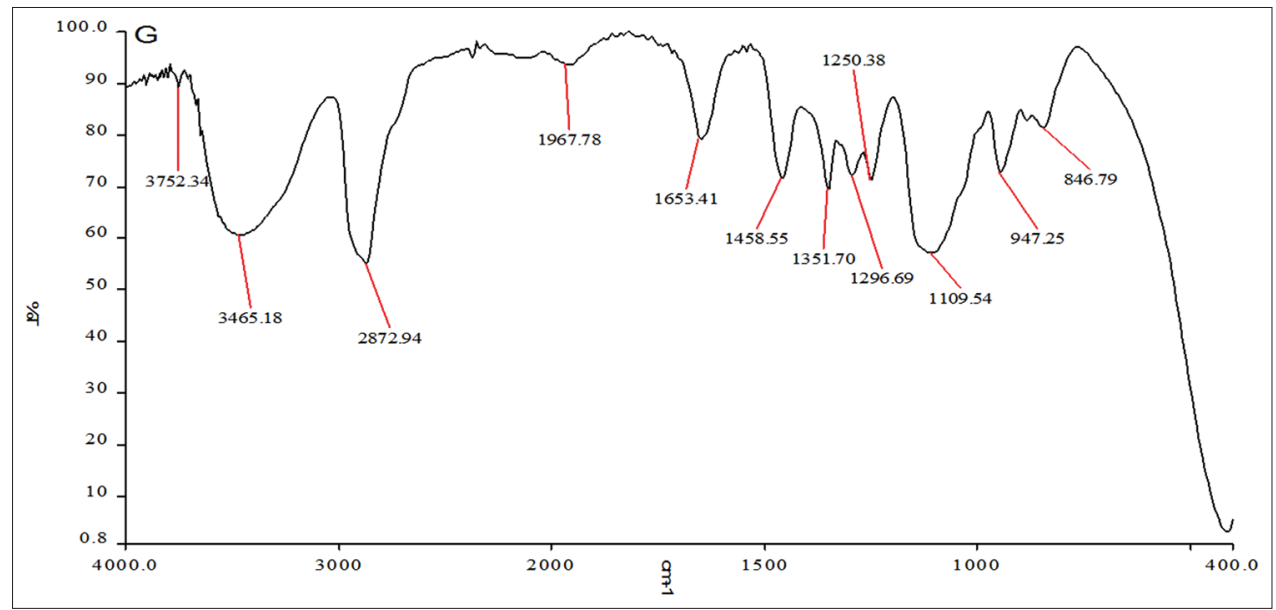

Fig. 8: Fourier-transform infrared spectrum obtained after mixing polyethylene glycol $(20 \mathrm{ml})$ with silver nitrate $(10 \mathrm{mg})$ and polyvinylpyrrolidone $(20 \mathrm{mg}$ ) - Microwave for $5 \mathrm{~min}$

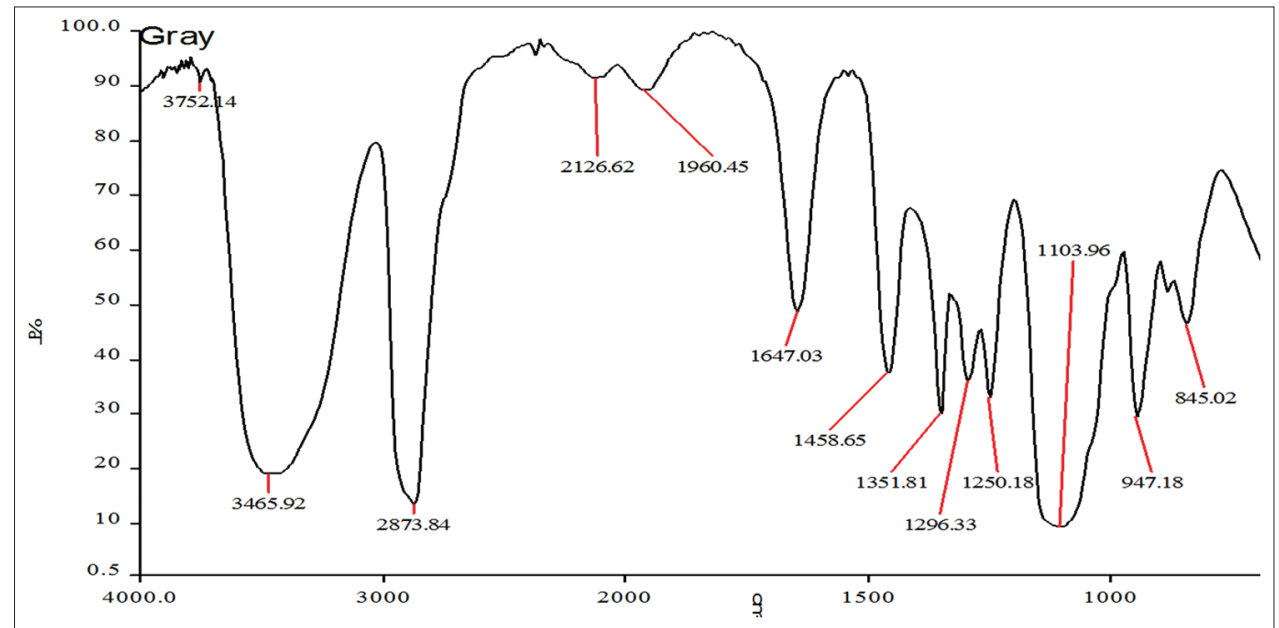

Fig. 9: Fourier-transform infrared spectrum obtained after mixing polyethylene glycol $(20 \mathrm{ml})$ with silver nitrate $(10 \mathrm{mg})$ and polyvinylpyrrolidone $(20 \mathrm{mg}$ ) in $\mathrm{KCl}-$ Microwave for $5 \mathrm{~min}$

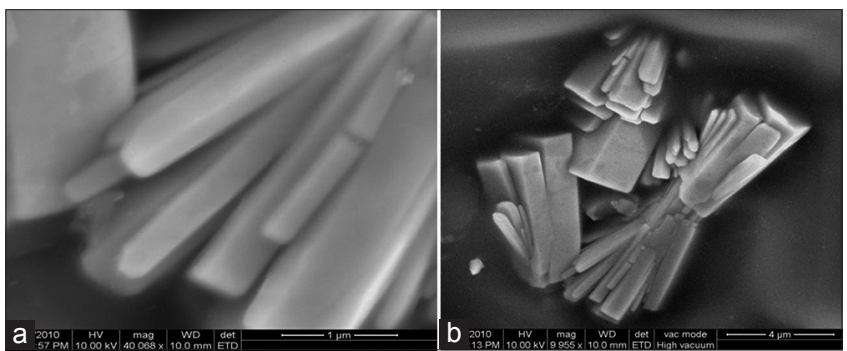

Fig. 10: ( $a$ and b) Scanning electron microscopy images of polyethylene glycol-protected silver nanoparticles in the presence of $\mathrm{KCl}(0.1 \mathrm{M})$ under microwave heating and subsequent UV irradiation

the drug along with the AgNPs could be due to any of the different mechanisms that silver uses against the bacterial pathogens. AgNPs may attach to the surface of the bacterial cell membrane and disturb its power functions such as permeability and respiration by impairing ATP synthesis [15]. Silver ions have also been shown, to penetrate into the bacterial cell and thereby cause damage to phosphorus and sulfur containing compounds such as DNA and proteins [16]. This is achieved predominantly by the process of denaturation. The release of silver from the nanoparticle could additionally contribute to the bactericidal properties of the nanoparticles. Bacterial cell lysis and modulation of the protein profile of the bacteria have also been shown to be the reasons for the bactericidal activity of silver [17]. In the present study, the results show a synergistic effect of vancomycin in the presence of AgNPs.

The average size of the synthesized silver colloid particles ranged from 40 to $200 \mathrm{~nm}$, depending on the concentration of PVP and on the type of reducing agents in the reaction system. It is reported that the bactericidal effect of AgNPs decreases as the size increases and is also affected by the shape of the particles. Thus, the increased activity of the AgNPs could be attributed to the small size of the nanoparticles [18]. Pal et al. demonstrated that AgNPs had increased antibacterial activity against $E$. coli compared to $\mathrm{Ag}^{+}$ions in the form of $\mathrm{AgNO}_{3}$ and proposed that nonmaterial such as $\mathrm{Ag}(\mathrm{III})$ crystals synergistically promoted the antibacterial effect against $E$. coli [19]. Similar results were shown by others also. Recently, many research groups have worked to synthesize the silver functionalized vancomycin for targeted drug delivery. Then, the functionalized drug easily forms a monolayer assembly when the drug was allowed to equilibrate the AgNPs. These methods are exploited for drug delivery of controlled and relaxed antibiotic to avoid side effects of overdosage [20] (Fig. 12).

\section{CONCLUSION}

Polyol process is a simple and efficient method for synthesizing AgNPs. We have synthesized AgNPs and nanorods using polyol method under 
Table 1: Antibacterial activity of silver nanoparticles on various microorganisms

\begin{tabular}{llll}
\hline Microorganisms & \multicolumn{2}{l}{ Zone of inhibition $(\mathbf{m m})$} & \\
\cline { 2 - 4 } & Vancomycin (standard) $\mathbf{1 0} \mathbf{u g} / \mathbf{m l}$ & Silver nanoparticle 10 ug/ml & Vancomycin+Silver nanoparticle 10 ug/ml \\
\hline Klebsiella pneumoniae & 21 & 19 & 39 \\
Escherichia coli & 24 & 20 & 40 \\
Staphylococcus aureus & 23 & 21 & 41 \\
Micrococcus luteus & 21 & 20 & 40 \\
\hline
\end{tabular}

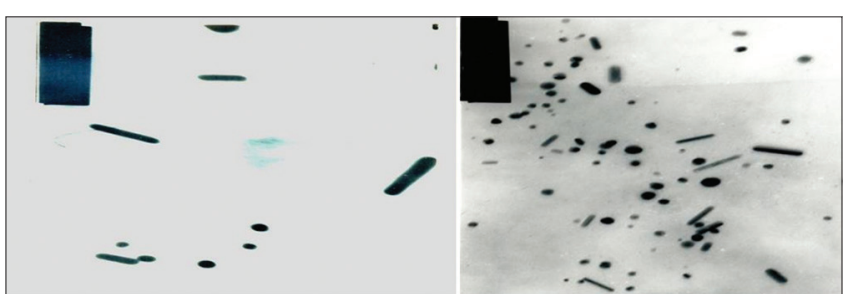

Fig. 11: Transmission electron microscopy images of polyethylene glycol-protected silver nanoparticles in the presence of $\mathrm{KCl}$

(0.1 M) synthesized under microwave heating and subsequent UV irradiation
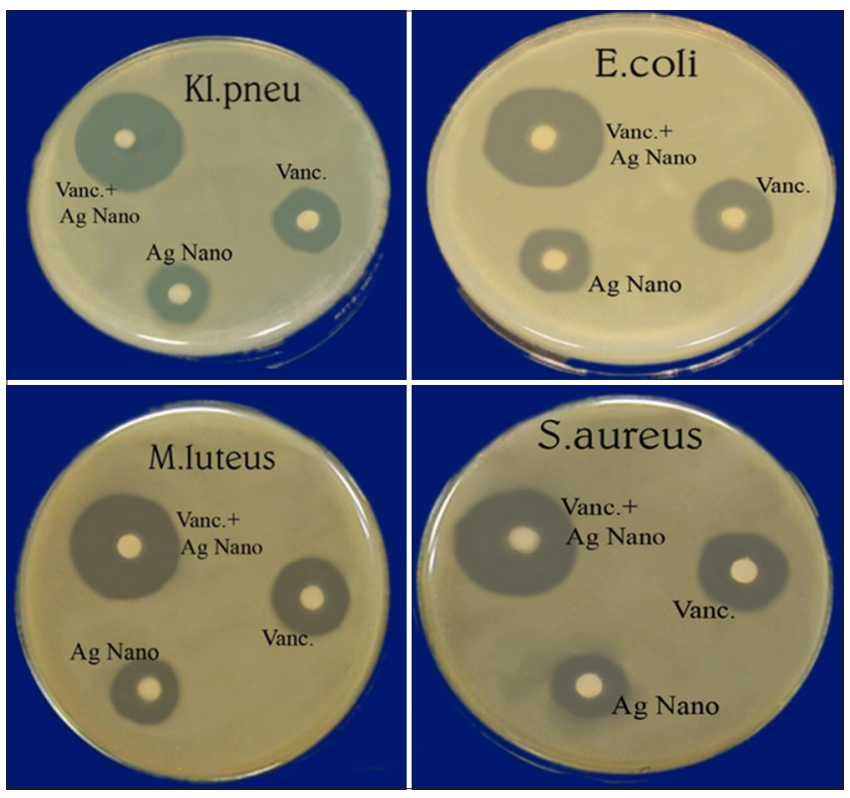

Fig. 12: Photograph images of the zones of inhibition of polyethylene glycol-protected silver nanoparticles by Kirby-Bauer test with standard antibiotic vancomycin

MW heating. Furthermore, we have observed that a catalytic amount of $\mathrm{KCl}$ and $\mathrm{Fe}^{2+}$ greatly influences the growth of AgNP size and shape. Uniform and stable polymer protected AgNPs were synthesized using ethylene glycol, diethylene glycol, triethylene glycol, and PEG as reducing agents in the presence of PVP under MW mode of heating. In the case of long-chain polyhydric ethylene glycol and PVP as the reaction medium, both PVP and PEG played a dual role as a reducing as well as shape directing agents, and thereby, the AgNPs were stabilized by both the polymers. From UV-visible spectroscopy studies, the growth rate was confirmed by measuring the change in absorbance of plasmon peak shape at different time intervals. The binding of vancomycin antibiotic on PEG-protected AgNP surface was confirmed by UV-visible spectral studies. FTIR spectroscopy studies showed the changes in the metal and the capping agents that result in the formation of PEG-protected AgNPs. SEM and TEM images revealed that very stable colloidal solutions of AgNPs with almost spherical and rod shape along with high monodispersity can be obtained with PEG-protected AgNPs. Finally, the antibacterial activity of PEG-protected AgNPs was investigated, which showed a synergistic role for the AgNPs along with vancomycin. Thus, this study shows the potential synergistic role that AgNPs play along with established drugs; however, further studies are needed to functionally characterize their antibacterial activity.

\section{ACKNOWLEDGMENT}

The authors acknowledge for the facilities provided in IIT-Madras (SAIF) for recording various spectra.

\section{AUTHOR'S CONTRIBUTIONS}

D. Malathy conducted the study, Meyappan Revathi planned and designed the study, and M. Letticia supported the conduction of the study.

\section{CONFLICTS OF INTEREST}

Authors declare that they have no conflicts of interest. All authors have equally contributed to this article.

\section{REFERENCES}

1. Suramwara NV, Thakareb SR, Khatya NT. One pot synthesis of copper nanoparticles at room temperature and its catalytic activity. Arab J Chem 2016;9:1807-12

2. Pillai ZS, Kamat PV. What factors control the size and shape of silver nanoparticles in the citrate ion reduction method. J Phys Chem B 2004;108:945-51.

3. Abedini A, Daud AR, Hamid MA, Othman NK, Saion E. A review on radiation-induced nucleation and growth of colloidal metallic nanoparticles. Nanoscale Res Lett 2013;8:474-8.

4. Mizukoshi $\mathrm{Y}$, Fujimoto $\mathrm{T}$, Nagata $\mathrm{Y}$, Oshima $\mathrm{R}$, Maeda $\mathrm{Y}$. Characterization and catalytic activity of core-shell structured gold/ palladium bimetallic nanoparticles synthesized by the son chemical method. J Phys Chem B 2000;104:6028-32

5. Mathew DS, Juang RS. An overview of the structure and magnetism of spinel ferrite nanoparticles and their synthesis in microemulsions. Chem Eng J 2007;129:51-65

6. Dang TM, Le TT, Fribourg-Blanc E, Dang MC. Influence of surfactant on the preparation of silver nanoparticles by polyol method. Adv Natl Sci 2012;3:1-4.

7. Guzman M, Dille J, Godet S. Synthesis and antibacterial activity of silver nanoparticles against gram-positive and gram-negative bacteria. Nanomedicine 2012;8:37-45.

8. Pal PA, Devi SS. Microwave-assisted synthesis of silver nanoparticles using ethanol as a reducing agent. Mater Chem Physics 2009;114:530-2.

9. Murugesan S, Bhuvaneswari S, Sivamurugan V. Green synthesis, characterization of silver nanoparticles of a marine red alga spyridia fusiformis and their antibacterial activity. Int J Pharm Pharm Sci 2017;9:192-7.

10. Wang Y, Zheng Y, Huang CZ, Xia Y. Synthesis of Ag Nano cubes 18$32 \mathrm{~nm}$ in edge length: The effects of polyol on reduction kinetics, size control, and reproducibility. J Am Chem Soc 2013;135:1941-51.

11. Zhang S, Tang Y, Vlahovic B. Review on preparation and applications of silver-containing nanofibers. Nanoscale Res Lett 2016;11:80-5.

12. Iravani S, Korbekandi H, Mirmohammadi SV, Zolfaghari SV. Synthesis of silver nanoparticles: Chemical, physical and biological methods. Res Pharm Sci 2014;9:385-406.

13. Das R, Nath SS, Chakdar D, Gope G, Bhattacharjee R. Preparation of silver nanoparticles and their Characterization. J Mater 2009;5:1-6.

14. Moore TL, Rodriguez-Lorenzo L, Hirsch V, Balog S, Urban D, Jud C, et al. Nanoparticle colloidal stability in cell culture media and impact 
on cellular interactions. Chem Soc Rev 2015;44:6287-305.

15. Dibrov P, Dzioba J, Gosink KK, Hase CC. Chemiosmotic mechanism of antimicrobial activity of $\mathrm{Ag}(+)$ in Vibrio cholerae. Antimicrob Agents Chemother 2002;46:2668-70.

16. Dakal TC, Kumar A, Majumdar RC, Yadav V. Mechanistic basis of antimicrobial actions of silver nanoparticles. Front Microbiol 2016;7:1831.

17. Sridevi A, Sandhya A, Devi PS. Characterization and antibacterial studies of leaf assisted silver nanoparticles from Carica papaya: A green synthetic approach. Int J Pharm Pharm Sci 2015;7:143-6.
18. Baker C, Pradhan A, Pakstis L, Pochan DJ, Shah SI. Synthesis and antibacterial properties of silver nanoparticles. J Nanosci Nanotechnol 2005;5:244-9.

19. Pal S, Tak YK, Song JM. Does the antibacterial activity of silver nanoparticles depend on the shape of the nanoparticle? A study of the gram-negative bacterium Escherichia coli. Appl Environ Microbiol 2007:73:1712-20

20. Ahmad U, Faiyazuddin MD. Smart nanobots: The future in nanomedicine and biotherapeutics. J Nanomed Biother Discov 2016;6:e140 